\title{
NÍVEIS DE LISINA DIGESTÍVEL PARA POEDEIRAS SEMIPESADAS COM DUAS CATEGORIAS DE PESO
}

\author{
LEITE, Paulo Ricardo de Sá da Costa ${ }^{1}$; \\ LEANDRO, Nadja Susana Mogyca ${ }^{1}$; \\ CARVALHO, Heloisa Helena de ${ }^{1}$; \\ OLIVEIRA, Eduardo Mirando de ${ }^{1}$; \\ PEREIRA, Marcela Luzia Rodrigues ${ }^{1}$.
}

\section{RESUMO}

$\mathrm{O}$ bjetivou-se determinar a exigência de lisina digestível na dieta de postura (28 a 40 semanas) de poedeiras com duas categorias de peso corporal. Foram utilizadas 400 poedeiras semipesadas da linhagem Embrapa 031, em pico de postura, com peso considerado leve $(1.630 \mathrm{~g})$ e padrão $(1.830 \mathrm{~g})$, sendo estudado níveis de lisina digestível $(0,590,0,690,0,790$ e $0,890 \%)$ em delineamento em blocos ao acaso em esquema fatorial 2 x 4 (duas categorias de peso x quatro níveis de lisina digestível), com cinco repetições e 10 aves por parcela. Foram avaliados a digestibilidade dos nutrientes da dieta na 32 a semana, desempenho zootécnico e qualidade de ovos durante três ciclos de 28 dias, além do desenvolvimento do aparelho reprodutor. Os dados foram submetidos à análise de variância e a regressão polinomial. As aves de maior peso apresentaram maior consumo de ração e maior peso dos ovos. Não houve efeito do peso das aves sobre o percentual de albúmen, gema, casca, espessura de casca e unidade Haugh. As aves de peso leve obtiveram maior peso relativo do oviduto, no entanto não houve efeito do peso sobre o comprimento e número de pregas do magno e istmo. Houve efeito quadrático positivo dos níveis de lisina digestível sobre os resultados de ingestão de nitrogênio, balanço de nitrogênio e balanço de nitrogênio por massa de ovo. Conclui-se que níveis crescentes de lisina digestível não proporcionaram melhores resultados no desempenho e qualidade de ovos. Recomenda-se o nível de $0,590 \%$ de lisina digestível na ração de postura, o que corresponde ao consumo de $577 \mathrm{mg} / \mathrm{ave} / \mathrm{dia}$.

Palavras-chave: Aminoácido. Digestibilidade. Embrapa. Oviduto. 


\section{INTRODUÇÃO}

O peso corporal da poedeira no início da postura quando abaixo do estabelecido pelo manual de cada linhagem pode refletir nos resultados de desempenho durante todo o período de produção e, além disso, o peso da ave apresenta correlação positiva com o peso do ovo (GOMES JÚNIOR, 2008; INOUE et al., 2006) e também pode influenciar a qualidade e os percentuais dos componentes dos ovos (KIRIKC et al., 2007).

Durante o pico de postura, a produção de ovos pode alcançar percentuais superiores a 90\%, sendo, provavelmente, o período em que ocorre maior demanda de nutrientes, principalmente a de aminoácidos (JORDÃO FILHO et al., 2006). Os aminoácidos são importantes para a manutenção do peso corporal da ave e da produção de ovos. Dentre eles, destaca-se o aminoácido lisina, que é considerado fisiologicamente essencial para mantença, crescimento e produção das aves e tem como principal função a síntese de proteína muscular (JARDIM FILHO et al., 2008; ROCHA et al., 2009; SÁ et al., 2007).

Para aves que apresentam peso corporal abaixo do recomendado é importante a formulação de dieta com maior densidade nutricional para conter níveis mais elevados de nutrientes, tentando através do ajuste da formulação das dietas recuperar e assegurar o peso corporal das aves (HY-LINE, 2009).

Em estudo com poedeiras leves, no período de 24 a 40 semanas, Rocha et al. (2009) verificaram que maiores níveis de lisina digestível proporcionaram acréscimo linear do peso corporal das aves, particularmente quando havia um consumo médio diário por ave de 759 mg de lisina. Estes mesmos autores também observaram que a maior produção dos ovos ocorreu no maior nível estudado sendo recomendado 0,770\% de lisina digestível. Rostagno et al. (2011) recomendaram $0,733 \%$ de lisina digestível para poedeiras semipesadas com 28 semanas.

Aves que iniciam a produção de ovos abaixo do peso proposto pelo manual da linhagem não atingem a produção de pico esperada ou não conseguem mantê-lo por mais que algumas semanas. Assim, níveis crescentes de lisina na ração de pico de postura poderá proporcionar aumento do peso corporal com consequente melhor produção e qualidade de ovos. 
Objetivou-se avaliar o efeito de níveis crescentes de lisina digestível na ração de poedeiras semipesadas da linhagem Embrapa 031 com duas categorias de peso sobre a recuperação do peso corporal, digestibilidade dos nutrientes da dieta, produção e qualidade de ovos e desenvolvimento do aparelho reprodutor.

\section{MATERIAL E MÉTODOS}

Foram utilizadas 400 poedeiras semipesadas da linhagem Embrapa 031 com 28 semanas de idade em fase de pico de postura. O período experimental compreendeu de 28 a 40 semanas de idade, sendo avaliados três ciclos de produção de ovos, de 28 dias cada. Até as 27 semanas de idade, o manejo das aves seguiu as recomendações do manual da linhagem Embrapa 031. Com 28 semanas de idade as aves foram divididas em dois grupos de peso: peso leve, com média de $1.630 \mathrm{~g}$ e peso padrão (de acordo com o manual da linhagem) com média de peso vivo de $1.830 \mathrm{~g}$, sendo considerado na seleção das aves um desvio padrão de $10 \%$. As médias de peso corporal de poedeiras semipesadas com duas categorias de peso às 28 semanas de idade, início do período experimental, foram de 1,696 kg (leve) e 1,808 kg (padrão), sendo que o coeficiente de variação foi de $3,58 \%$.

Os tratamentos estudados foram duas categorias de peso combinados com quatro níveis de lisina digestível na ração de postura. Foi utilizado o delineamento em blocos ao acaso (considerando o fator bloco o andar da gaiola) com oito tratamentos em esquema fatorial 2 x 4 (dois pesos x quatro níveis de lisina), cinco repetições com 10 aves por unidade experimental. As dietas experimentais (Tabela 1) foram isonutritivas e formuladas de acordo com as exigências nutricionais propostas por Rostagno et al. (2005), exceto para os níveis de lisina digestível. Os níveis nutricionais de lisina digestível das dietas foram obtidos a partir do acréscimo de lisina em substituição ao amido da dieta basal de forma a atender os níveis propostos: $0,590,0,690,0,790$ e 0,890\% de lisina digestível na ração. 
Tabela 1 - Ingredientes e composição nutricional da dieta basal.

\begin{tabular}{lc}
\hline Ingredientes (\%) & \\
\hline Milho & 62,583 \\
Farelo de Soja & 16,010 \\
Calcário calcítico & 8,350 \\
Farelo de Trigo & 10,09 \\
Fosfato Bicálcico & 1,125 \\
Amido & 1,00 \\
Premix & 0,300 \\
Sal Comum & 0,408 \\
DL-Metionina & 0,117 \\
L-lisina HCl & 0,012 \\
Total & 100 \\
\hline Composição calculada & \\
\hline Proteína Bruta (\%) & 14,41 \\
EM (kcal/kg) & 2.700 \\
Cálcio (\%) & 3,568 \\
P disponível (\%) & 0,318 \\
Lisina digestível (\%) & 0,590 \\
Met + cist digestível (\%) & 0,537 \\
Metionina digestível (\%) & 0,323 \\
Ácido linoléico (\%) & 1,463 \\
Arginina digestível (\%) & 0,833 \\
Sódio (\%) & 0,195 \\
Treonina digestível (\%) & 0,459 \\
Triptofano digestível (\%) & 0,143 \\
\hline 'Suplemento mineral e vitamínico para poedeiras (composição/kg do produto): halquinol $6.666,67 \mathrm{mg}$, \\
manganês 33.333 mg, zinco 26.666,67 mg, ferro 16.666,67 mg, cobre 2.666,67 mg, iodo 250 mg, vitamina A \\
2.666.667 Ul, vitamina E 1.8333,33 mg, etoxiquin 678,49 mg, vitamina D3 600.000 Ul, vitamina K3 400 mg, \\
vitamina B1 333,33 mg, vitamina B2 1.000 mg, vitamina B6 566,67 mg, vitamina B12 2.666,67 mcg, niacina \\
6.000 mg, colina 25.316,67 mg, ácido fólico 93,33 mg, ácido pantotênico 2.166,67 mg, selênio 93,33 mg. \\
\hline
\end{tabular}

O programa de luz foi utilizado de acordo com a recomendação do manual da linhagem com 16 horas de luz por dia, durante todo o período experimental. A iluminação ocorreu por meio de lâmpadas incandescentes controladas por um relógio automático (timer). A temperatura e umidade relativa foram registradas durante todo o período do experimento.

As aves passaram por um período de adaptação de uma semana recebendo as dietas experimentais de acordo com os tratamentos. Na 32a semana de idade foi realizado um ensaio de metabolismo pelo método de coleta total de excretas. Para o ensaio metabólico oitenta aves foram separadas aleatoriamente e dispostas em gaiolas com bandejas coletoras. Foram testados os oito tratamentos, com cinco repetições, sendo duas aves por parcela. 
As excretas foram coletadas duas vezes ao dia durante quatro dias consecutivos e acondicionadas em sacos plásticos identificados, congeladas para conservação e posteriores análises bromatológicas. As análises foram realizadas no Laboratório de Nutrição Animal do Departamento de Produção Animal da Escola de Veterinária e Zootecnia da Universidade Federal de Goiás, segundo a metodologia preconizada por Silva e Queiroz (2002). Com os resultados das análises bromatológicas foram calculados os coeficientes de metabolizabilidade da gordura, determinado o balanço de nitrogênio e o balanço de nitrogênio por massa de ovo produzida.

Às 34 semanas de idade, quatro aves por tratamento foram selecionadas para avaliação morfométrica dos órgãos do sistema reprodutor e percentual de gordura abdominal. Para o sistema reprodutor foram pesados o ovário e oviduto e realizadas as mensurações de parte do oviduto (infundíbulo, magno, istmo e útero) e contagem do número de pregas do magno e istmo. Para avaliação dos resultados de desempenho zootécnico e qualidade de ovos foram considerados três ciclos de 28 dias, e no final de cada ciclo, avaliados os resultados de peso corporal, consumo de ração (g/ave/dia), consumo de lisina, conversão alimentar $(\mathrm{kg} / \mathrm{kg}$ e kg/dúzia de ovos), peso e a massa do ovo e produção de ovos.

Para avaliação da qualidade dos ovos, nos últimos três dias de cada ciclo, quatro ovos por parcela foram selecionados e pesados para realização da densidade específica. Posteriormente, os ovos foram quebrados em superfície plana para avaliação do peso da casca, espessura da casca, índice de gema e albúmen, percentual de gema, casca e albúmen e unidade Haugh, que foi calculada utilizando a seguinte fórmula: $U H=100 \log (H-1,7 p+$ 7,6), em que: $\mathrm{UH}=$ unidade Haugh; $\mathrm{H}=$ altura de albúmen denso $(\mathrm{mm}) ; \mathrm{p}=$ peso do ovo $(\mathrm{g})$, conforme Cotta (1997).

Os dados foram submetidos à análise de variância e regressão polinomial para os níveis de lisina digestível na ração, com auxílio do programa estatístico SAS (2000).

\section{RESULTADOS E DISCUSSÃO}

Não houve interação $(p>0,05)$ entre os fatores estudados para os resultados de ingestão e excreção de nitrogênio, balanço de nitrogênio, balanço de nitrogênio por massa de ovos e 
Tabela 3 - Peso corporal, consumo de ração (CR), conversão alimentar (CA) e ingestão de lisina de poedeiras semipesadas com duas categorias de peso no período de 28 a 40 semanas de idade alimentadas com diferentes níveis de lisina digestível.

\begin{tabular}{|c|c|c|c|c|c|}
\hline Peso & Peso da ave (g) & CR (g/ave/dia) & $\mathrm{CA}(\mathrm{kg} / \mathrm{kg})$ & $\mathrm{CA}(\mathrm{kg} / \mathrm{dz})$ & $\begin{array}{c}\text { Ingestão de lisina } \\
\text { (mg/ave/dia) }\end{array}$ \\
\hline Leve & $1,649^{b}$ & $100,23^{b}$ & 2,268 & 1,554 & $720^{b}$ \\
\hline Padrão & $1,767^{a}$ & $104,77^{a}$ & 2,275 & 1,604 & $753^{a}$ \\
\hline \multicolumn{6}{|c|}{ Lisina Digestível (\%) } \\
\hline 0,590 & 1,696 & 101,49 & 2,269 & 1,554 & $577^{d}$ \\
\hline 0,690 & 1,717 & 102,67 & 2,266 & 1,580 & $686^{c}$ \\
\hline 0,790 & 1,717 & 102,79 & 2,292 & 1,589 & $790^{b}$ \\
\hline 0,890 & 1,700 & 103,06 & 2,258 & 1,593 & $895^{a}$ \\
\hline \multicolumn{6}{|c|}{ Valor de $p$} \\
\hline Peso & 0,0001 & 0,002 & 0,867 & 0,082 & 0,006 \\
\hline Lisina & 0,913 & 0,909 & 0,939 & 0,784 & 0,0001 \\
\hline Peso x Lisina. & 0,283 & 0,939 & 0,153 & 0,174 & 0,807 \\
\hline CV (\%) & 3,27 & 4,38 & 5,40 & 5,59 & 17,02 \\
\hline
\end{tabular}

Médias seguidas por letras distintas na mesma coluna diferem entre si pelo teste $F(5 \%)$.

Houve efeito $(p<0,05)$ do peso da ave sobre o consumo de ração e consumo de lisina digestível (Tabela 3). As poedeiras com menor peso corporal ingeriram menos ração, o que refletiu menor consumo de lisina digestível, quando comparadas com poedeiras de peso padrão. Com relação aos diferentes níveis de lisina digestível na ração, não foi observado efeito $(p>0,05)$ para nenhuma das variáveis de desempenho (Tabela 3 ). O aumento dos níveis de lisina digestível não proporcionou maior peso corporal das poedeiras em todo o período experimental. Por outro lado, Rocha et al. (2009) verificaram acréscimo do peso corporal de poedeiras Hy-Line W36 no período de 24 a 40 semanas quando alimentadas com rações de postura contendo níveis crescentes de lisina digestível $(0,545 ; 0,590 ; 0,635 ; 0,680$; $0,725$ e $0,770 \%)$ e recomendaram o nível de $0,770 \%$.

Não houve interação $(p>0,05)$ entre os fatores estudados para os resultados de peso, produção e massa de ovos (Tabela 4). Houve efeito do peso da poedeira sobre o peso e a massa de ovos. Foi observada $(p<0,05)$ maior massa de ovos para poedeiras com maior peso corporal, provavelmente em função do maior peso dos ovos das poedeiras de maior peso corporal. 
Tabela 4 - Peso do ovo (PO), produção de ovos e massa de ovos de poedeiras semipesadas com duas categorias de peso no período de 28 a 40 semanas de idade alimentadas com diferentes níveis de lisina digestível.

\begin{tabular}{|c|c|c|c|}
\hline Peso & $\mathrm{PO}(\mathrm{g})$ & Produção de ovos (\%) & Massa de ovos (g/ave/dia) \\
\hline Leve & $57,26^{b}$ & 79,56 & $47,52^{b}$ \\
\hline Padrão & $59,00^{a}$ & 80,52 & $49,75^{a}$ \\
\hline \multicolumn{4}{|c|}{ Lisina Digestível (\%) } \\
\hline 0,605 & 57,16 & 79,56 & 48,26 \\
\hline 0,679 & 58,42 & 80,64 & 48,91 \\
\hline 0,755 & 57,99 & 80,14 & 48,27 \\
\hline 0,830 & 58,94 & 79,81 & 49,11 \\
\hline \multicolumn{4}{|c|}{ Valor de $p$} \\
\hline Peso & 0,0001 & 0,546 & 0,035 \\
\hline Lisina & 0,120 & 0,969 & 0,906 \\
\hline Peso x Lisina & 0,876 & 0,460 & 0,332 \\
\hline CV (\%) & 2,57 & 6,25 & 6,60 \\
\hline
\end{tabular}

Foi verificado efeito $(p<0,05)$ do peso da ave sobre o peso do ovo. As poedeiras com peso padrão apresentaram ovos mais pesados que aves de menor peso corporal (Tabela 4), o que está de acordo com outros estudos (ALKAN et al., 2010; HAQ et al., 2011; UDEH, 2007). Gomes Júnior (2008) relatou que aves leves, abaixo do peso recomendado pela linhagem, provocam grandes prejuízos, pois existe correlação positiva entre peso da ave e peso ovo, além do fato que aves abaixo do peso apresentam baixa produtividade.

Níveis crescentes de lisina digestível na ração não influenciaram $(p>0,05)$ o peso e a produção de ovos (Tabela 4). No entanto, Rocha et al. (2009), verificaram que poedeiras leves da linhagem Hy-Line apresentaram, no período de 24 a 40 semanas, maior produção de ovos quando alimentadas com maior nível de lisina digestível, especialmente no nível de 0,770\%. Novak et al. (2004) reportaram efeito de maior nível de lisina sobre o peso do ovo. Os autores verificaram que poedeiras Dekalb (44 a 63 semanas) que consumiram $860 \mathrm{mg} / \mathrm{dia}$ de lisina digestível na ração de postura apresentaram ovos menos pesados (60 g) quando comparadas com poedeiras que consumiram $959 \mathrm{mg} / \mathrm{dia}(62 \mathrm{~g})$. Outras pesquisas também mostraram que ocorre maior peso de ovos em poedeiras alimentadas com dietas suplementadas com maiores níveis de lisina (ROCHA et al., 2009; SÁ et al., 2007).

Não houve interação entre os fatores estudados $(p>0,05)$ para os resultados de percentual dos componentes dos ovos (albúmen e gema), índices (gema e albúmen) e unidade Haugh, assim como não houve efeito do peso da ave para estes resultados (Tabela 5). Não foi 
observado efeito $(p>0,05)$ da lisina digestível sobre o percentual de albúmen e de gema, índices de gema e de albúmen e unidade Haugh (Tabela 5). Da mesma maneira Rocha et al. (2009) não observaram efeito de níveis crescentes de lisina digestível na fase de postura (24 a 40 semanas) sobre a qualidade interna e componentes dos ovos. Do mesmo modo, Jardim Filho et al. (2010) não relataram influência da lisina digestível na ração de postura de poedeiras HY-Line W36 sobre a qualidade dos ovos.

Tabela 5 - Percentual de albúmen, percentual de gema, índice de albúmen (IA), índice de gema (IG) e unidade Haugh (UH) de ovos de poedeiras semipesadas com duas categorias de peso no período de 28 a 40 semanas de idade alimentadas com diferentes níveis de lisina digestível.

\begin{tabular}{lccccc}
\hline Peso & Albúmen (\%) & Gema (\%) & IA & IG & UH \\
\hline Leve & 65,51 & 24,37 & 0,146 & 0,458 & 96,74 \\
Padrão & 65,73 & 24,34 & 0,144 & 0,456 & 97,05 \\
\hline Lisina Digestível (\%) & & & & & \\
\hline 0,605 & 65,59 & 24,36 & 0,145 & 0,458 & 96,59 \\
0,679 & 65,76 & 24,33 & 0,147 & 0,458 & 97,27 \\
0,755 & 65,52 & 24,37 & 0,145 & 0,455 & 96,85 \\
0,830 & 65,62 & 24,35 & 0,144 & 0,458 & 96,88 \\
\hline \multicolumn{7}{c}{ Valor de p } & & & & \\
\hline Peso & 0,278 & 0,837 & 0,653 & 0,552 & 0,657 \\
Lisina & 0,873 & 0,997 & 0,937 & 0,791 & 0,926 \\
Peso x Lisina & 0,164 & 0,474 & 0,442 & 0,809 & 0,462 \\
\hline CV (\%) & 0,97 & 2,13 & 7,21 & 1,72 & 2,30 \\
\hline
\end{tabular}

Não houve interação $(p>0,05)$ entre os fatores peso da poedeira e nível de lisina digestível para os resultados de peso e espessura da casca e densidade específica dos ovos (Tabela 6). Não foi observado efeito $(p>0,05)$ do peso da ave sobre o percentual e espessura de casca. Da mesma forma, Lacin et al. (2008) não relataram efeito de três categorias de peso de poedeiras Lohmann na espessura de casca.

O peso da ave influenciou $(p<0,05)$ a densidade específica dos ovos (Tabela 6$)$. As poedeiras com peso leve apresentaram melhor resultado de densidade específica quando comparadas com as aves de maior peso corporal.

Não houve efeito $(p>0,05)$ dos níveis de lisina digestível sobre as variáveis de qualidade de casca, o que concorda com os resultados de Novak et al. (2004), Jordão Filho et al. (2006), Jardim Filho et al. (2008) e Matos et al. (2009). 
Tabela 6 - Percentual de casca, espessura de casca (EC) e densidade específica (DE) de ovos de poedeiras semipesadas com duas categorias de peso no período de 28 a 40 semanas de idade alimentadas com níveis crescentes de lisina digestível.

\begin{tabular}{lccc}
\hline Peso & Casca (\%) & EC (mm) & DE $\left(\mathrm{g} / \mathrm{cm}^{3}\right)$ \\
\hline Leve & 10,12 & 0,42 & $1,097^{\mathrm{a}}$ \\
Padrão & 10,02 & 0,41 & $1^{\mathrm{b}} 096^{\mathrm{b}}$ \\
\hline Lisina Digestível (\%) & & & 1,097 \\
\hline 0,590 & 10,11 & 0,42 & 1,097 \\
0,690 & 10,04 & 0,42 & 1,097 \\
0,790 & 10,09 & 0,42 & 1,096 \\
0,890 & 10,04 & 0,42 & 0,003 \\
\hline \multicolumn{2}{c}{ Valor de p } & 0,943 \\
\hline Peso & 0,171 & 0,087 & 0,504 \\
Lisina & 0,884 & 0,991 & 0,09 \\
\hline Peso x Lisina & 0,239 & 0,519 & 1,92 \\
\hline
\end{tabular}

Médias seguidas por letras distintas na mesma coluna diferem entre si pelo teste $\mathrm{F}(5 \%)$.

Não houve interação entre os fatores estudados $(p>0,05)$ para os resultados de peso do ovário e oviduto (Tabela 7). Foi verificado efeito $(p<0,05)$ do peso da ave sobre o peso relativo do oviduto (Tabela 7). As poedeiras com peso leve apresentaram maior peso relativo do oviduto, em função do menor peso corporal. Níveis crescentes de lisina digestível na dieta não proporcionaram efeito $(p>0,05)$ sobre o peso do aparelho reprodutor. Da mesma maneira, Basiouni et al. (2006), Jardim Filho et al. (2008) e Jardim Filho et al. (2010) não encontraram efeito de níveis crescentes de lisina na ração de poedeiras sobre o desempenho reprodutivo das aves (peso do oviduto e peso do ovário).

Outros fatores podem estar envolvidos com o desenvolvimento do aparelho reprodutor das aves, tais como o nível de proteína bruta da dieta. Bunchasak e Silapasorn (2005) observaram que rações de poedeiras na fase de postura (24 a 44 semanas) com $16 \%$ de proteína bruta proporcionaram melhor desenvolvimento do aparelho reprodutor (peso do ovário e oviduto e comprimento do oviduto) quando comparadas com rações com $14 \%$ de proteína bruta, mesmo percentual do presente estudo. 
Tabela 7 - Peso (g e \%) do ovário e oviduto de poedeiras semipesadas com 34 semanas alimentadas com diferentes níveis de lisina digestível na ração de postura.

\begin{tabular}{lcccc}
\hline Peso & Ovário $(\mathrm{g})$ & Ovário $(\%)$ & Oviduto $(\mathrm{g})$ & Oviduto (\%) \\
\hline Leve & 38,28 & 1,81 & 66,83 & $3,799^{\mathrm{a}}$ \\
Padrão & 37,03 & 1,99 & 62,54 & $3,373^{\mathrm{b}}$ \\
\hline Lisina Digestível (\%) & & & 3,48 \\
\hline 0,590 & 40,50 & 1,98 & 67,06 & 3,48 \\
0,690 & 35,45 & 1,89 & 65,08 & 3,64 \\
0,790 & 40,60 & 1,79 & 66,26 & 3,72 \\
0,890 & 34,08 & 1,96 & 60,33 & 0,020 \\
\hline & & & 0,567 \\
\hline Peso & 0,643 & Valor de p & 0,206 & 0,285 \\
Lisina & 0,210 & 0,207 & 0,435 & 14,12 \\
\hline Peso x Lisina & 0,294 & 0,774 & 0,364 & 11,31 \\
\hline
\end{tabular}

Médias seguidas por letras distintas na mesma coluna diferem entre si pelo teste $\mathrm{F}(5 \%)$.

Não houve interação $(p>0,05)$ entre os fatores estudados para os resultados de comprimento do oviduto e número de pregas do magno e istmo. As mensurações do infundíbulo, magno, istmo e útero e o número de pregas do magno e istmo não foram influenciadas $(p>0,05)$ pelo peso da ave, assim como não houve efeito dos níveis crescentes de lisina digestível sobre estes resultados (Tabela 8). Nas pregas presentes na região do magno e útero estão localizadas as glândulas tubulares secretoras de, respectivamente, ovoalbumina e carbonato de cálcio. As pregas são importantes para a condução do ovo no oviduto. Wolfenson et al. (1982) relataram que a presença do ovo no útero está associada com aumento no suprimento sanguíneo e consequentemente com maior número de pregas no magno e no istmo em comparação com o oviduto que não possui ovo no seu interior. 
Tabela 8 - Comprimento do infundíbulo, magno, istmo, útero e número de pregas do magno e istmo de poedeiras semipesadas com 34 semanas alimentadas com diferentes níveis de lisina digestível na ração de postura.

\begin{tabular}{|c|c|c|c|c|c|c|}
\hline \multirow[b]{2}{*}{ Peso } & \multicolumn{4}{|c|}{ Comprimento $(\mathrm{cm})$} & \multicolumn{2}{|c|}{ №. Pregas } \\
\hline & Infundíbulo & Magno & Istmo & Útero & Magno & Istmo \\
\hline Leve & 8,77 & 36,44 & 13,17 & 5,12 & 19,93 & 16,81 \\
\hline Padrão & 8,60 & 35,82 & 13,13 & 5,03 & 20,80 & 16,26 \\
\hline \multicolumn{7}{|c|}{ Lisina Digestível (\%) } \\
\hline 0,590 & 7,73 & 35,40 & 14,15 & 4,62 & 19,75 & 15,62 \\
\hline 0,690 & 9,10 & 35,48 & 11,55 & 5,81 & 16,00 & 16,00 \\
\hline 0,790 & 8,67 & 34,57 & 13,11 & 4,85 & 17,42 & 17,42 \\
\hline 0,890 & 9,23 & 39,07 & 13,80 & 5,02 & 17,25 & 17,25 \\
\hline \multicolumn{7}{|c|}{ Valor de $p$} \\
\hline Peso & 0,747 & 0,644 & 0,961 & 0,862 & 0,308 & 0,474 \\
\hline Lisina & 0,179 & 0,062 & 0,112 & 0,427 & 0,332 & 0,235 \\
\hline Peso $x$ Lisina & 0,343 & 0,150 & 0,473 & 0,692 & 0,246 & 0,868 \\
\hline CV (\%) & 17,51 & 10,37 & 14,01 & 11,00 & 11,37 & 12,66 \\
\hline
\end{tabular}

\section{CONCLUSÃO}

Recomenda-se $0,590 \%$ de lisina digestível na dieta de postura de poedeiras semipesadas da linhagem Embrapa 031, de 28 a 40 semanas, o que corresponde ao consumo de 577 $\mathrm{mg} / \mathrm{ave} / \mathrm{dia}$, independente do peso da ave.

\section{DIGESTIBLE LYSINE LEVELS FOR LAYING HENS WITH TWO WEIGHT CATEGORIES}

\section{ABSTRACT}

$\mathrm{T}$ he objective was to determine the requirement of digestible lysine in the diet (28 to 40 weeks) of laying hens with two categories of body weight. Four hundred semi-heavy hens of the Embrapa 031 lineage were used, with a light weight $(1.630 \mathrm{~g})$ and standard $(1,830 \mathrm{~g})$, with digestible lysine levels $(0.590,0.690,0.790$ and $0.890 \%)$ being studied in a block design at random in a $2 \times 4$ factorial arrangement (two weight categories $\mathrm{x}$ four levels of digestible lysine), with five replicates and 10 birds per experimental unit. The nutrient digestibility of the diet in the $32 \mathrm{nd}$ week, the performance and the quality of eggs during three cycles of 28 days were evaluated, as well as the development of the reproductive system. Data were submitted to analysis of variance and polynomial regression. The higher weight birds presented higher feed intake and higher egg weight. There was no effect of bird weight on the percentage of albumen, yolk, shell, shell thickness and Haugh unit. The birds of light weight obtained greater relative weight of the oviduct, however there was no effect of weight on the length and number of folds of the magnum and isthmus. There was a 
positive quadratic effect of digestible lysine levels on nitrogen intake, nitrogen balance and nitrogen balance by egg mass. It was concluded that increasing levels of digestible lysine did not provide better egg quality and performance. The level of $0.590 \%$ of digestible lysine in the laying ration is recommended, which corresponds to the consumption of 577 $\mathrm{mg} / \mathrm{bird} / \mathrm{day}$.

Keywords: Amino acid. Digestibility. Embrapa. Oviduct.

\section{NIVELES DE LISINA DIGESTIBLE PARA PONEDORAS SEMIPESADAS CON DOS CATEGORÍAS DE PESO}

\section{RESUMEN}

$\mathrm{E}$ I objetivo fue determinar la exigencia de lisina digestible en la dieta de postura (28 a 40 semanas) de ponedoras, con dos categorías de peso corporal. Se utilizaron 400 ponedoras semipesadas de la marca comercial Embrapa 031, en pico de postura, con peso considerado leve $(1.630 \mathrm{~g})$ y patrón $(1.830 \mathrm{~g})$, siendo estudiado los niveles de lisina digestible $(0,590,0,690,0,790$ y $0,890 \%)$ en un diseño experimental en bloques al azar en esquema factorial $2 \times 4$ (dos categorías de peso x cuatro niveles de lisina digestible), con cinco repeticiones y 10 aves por parcela. Se evaluaron la digestibilidad de los nutrientes de la dieta en la 32a semana, desempeño zootécnico y calidad de huevos durante tres ciclos de 28 días, además del desarrollo del aparato reproductor. Los datos fueron sometidos al análisis de varianza y la regresión polinomial. Las aves de mayor peso presentaron mayor consumo de ración y mayor peso de los huevos. No hubo efecto del peso de las aves sobre el porcentaje de albumen, yema, corteza, espesor de cáscara y unidad Haugh. Las aves de peso ligero obtuvieron mayor peso relativo del oviducto, sin embargo, no hubo efecto del peso sobre la longitud y número de pliegues del magno e istmo. Se observó un efecto cuadrático positivo de los niveles de lisina digestible sobre los resultados de la ingestión de nitrógeno, balance de nitrógeno y balance de nitrógeno por masa de huevo. Se concluye que los niveles crecientes de lisina digestible no proporcionaron mejores resultados en el rendimiento y calidad de los huevos. Se recomienda el nivel de 0,590\% de lisina digestible en la ración de postura, lo que corresponde al consumo de $577 \mathrm{mg} / \mathrm{ave} /$ día.

Palabras clave: Aminoácido. Digestibilidad. Embrapa. Oviducto. 


\section{REFERÊNCIAS}

ALKAN, S.; KARABAG, K.; GALIÇ, A.; KARSLI, T.; et al. Effects of selection for body weight and egg production on egg quality traits in japanese quails (Coturnix japonica) of different lines and relationships between these traits. Kafkas Universitesi Veteriner Fakultesi Dergisi, Turkey, v. 16, n. 2, p. 239-244, 2010.

BASIOUNI, G.; NAJIB, H.; ZAKI, M. M.; AL-ANKARI, A. S. Influence of extra supplementation with arginine and lysine on overall performance, ovarian activities and humoral immune response in local saudi hens. International Journal Poultry Science, Faisalabad, v. 5, n. 5, p. 441-448, 2006.

BUNCHASAK, C.; SILAPASORN, T. Effects of adding methionine in low-protein diet on production performance, reproductive organs and chemical liver composition of laying hens under tropical conditions. International Journal Poultry Science, Faisalabad, v. 4, n. 5, p. 301-308, 2005.

COTTA, T. Reprodução da galinha e produção de ovos. Lavras: UFLA-FAEPE, 1997. 92p.

GOMES JÚNIOR, C. M. Fatores de manejo que afetam o desempenho da futura poedeira. In: CURSO DE ATUALIZAÇÃO EM AVICULTURA PARA POSTURA COMERCIAL, 5, 2008, Jaboticabal. ANAIS. Jaboticabal: UNESP, 2008. P. 63-68.

$H A Q$, R.; HAQ, E.; KHAN, M. F. Correlation between body weight \& egg weight of dokki and fayoumi hen in Pakistan. Journal of Basic and Applied Sciences, v. 7, n. 2, p. 165-168, 2011.

HY-LINE - Guia de manejo 2009-2011. Disponível em: http:// www.hylinedobrasil.com.br. Acesso em: 20 jan. 2013.

INOUE, A. Y.; ITO, D. T; SANTOS, I. L.; et al. Medidas de manejo para promoção de saúde das aves. In: CURSO DE ATUALIZAÇÃO EM AVICULTURA PARA POSTURA COMERCIAL, 3, 2006, Jaboticabal. ANAIS. Jaboticabal: UNESP, 2006. P. 63-68.

JARDIM FILHO, R. M.; STRINGHINI, J. H.; ANDRADE, M. A.; NUNES, A. B.; LEANDRO, N. S. M.; CAFÉ, M. B. Qualidade de ovos, parâmetros bioquímicos sanguíneos e desenvolvimento do aparelho reprodutor de poedeiras comerciais Lohmann LSL alimentadas com níveis crescentes de lisina digestível. Acta Scientiarum. Animal Science, v. 30, n. 1, p. 25-31, 2008.

JARDIM FILHO, R. M.; STRINGHINI, J. H.; ANDRADE, M. A.; CAFÉ, M. B.; LEANDRO, N. S. M.; CARVALHO, F. B. Níveis de lisina digestível para poedeiras Hy-Line W-36 em produção. Revista Brasileira de Zootecnia, Viçosa, v. 39, n. 4, p. 787-795, 2010.

JORDÃO FILHO, J.; SILVA, J. H. V.; SILVA, E. L.; RIBEIRO, M. L. G.; COSTA, F. G. P.; RODRIGUES, P. B. Exigência de lisina para poedeiras semipesadas durante o pico de postura. Revista Brasileira de Zootecnia, Viçosa, v. 35, n. 4, p. 1728-1734, 2006. 
KIRIKC, K.; GUNLU, A.; ÇETIN, O.; GARIP, M. Effect of hen weight on egg production and some egg quality characteristics in the Partridge (Alectoris graeca). Poultry Sciences, v. 86, n. 7, p. 1380-1383, 2007.

LACIN, E.; YILDIZ, A.; ESENBUGA, N.; MACIT, M. Effects of differences in the initial body weight of groups on laying performance and egg quality parameters of Lohmann laying hens. Czech Journal of Animal Science, v. 53, n. 11, p. 466-471, 2008.

MATOS, M. S.; LEANDRO, N. S. M.; STRINGHINI, J. H.; CAFÉ, M. B.; CARVALHO, F. B.; GOMES, N. A. Níveis de lisina e treonina digestíveis para poedeiras comerciais Lohmann LSL de 24 a 44 semanas de idade. Acta Scientiarum. Animal Science, Maringá, v. 31, n. 1, p. 19-24, 2009.

NOVAK, C.; YAKOUT, H.; SCHEIDELER, S. The combined effects of dietary lysine and total sulfur amino acid level on egg production parameters and egg components in Dekalb Delta laying hens. Poultry Science, Faisalabad, v. 83, n. 6, p. 977-984, 2004.

ROCHA, T. C.; GOMES, P. C.; DONZELE, J. L.; BARRETO, S. L. T.; MELLO, H. H. C.; BRUMANO, G. Níveis de lisina digestível em rações para poedeiras no período de 24 a 40 semanas de idade. Revista Brasileira de Zootecnia, Viçosa, v. 38, n. 9, p. 1726-1731, 2009.

ROSTAGNO, H. S.; ALBINO, L. F. T.; DONZELLE, J. F.; GOMES, P. C.; OLIVEIRA, R. F.; LOPES, D. C.; FERREIRA, A. S.; BARRETO, S. L. T. Tabelas brasileiras para aves e suínos. Composição de alimentos e exigências nutricionais. 2. ed. Viçosa: UFV, 2005. 186p.

ROSTAGNO, H. S.; ALBINO, L. F. T.; DONZELLE, J. F.; GOMES, P. C.; OLIVEIRA, R. F.; LOPES, D. C.; FERREIRA, A. S.; BARRETO, S. L. T.; EUCLIDES, R. F. Tabelas brasileiras para aves e suínos. Composição de alimentos e exigências nutricionais. 3. ed. Viçosa: UFV, 2011. 252p.

SÁ, L. M.; GOMES, P. C.; ROSTAGNO, H. S.; ALBINO, L. F. T.; D’AGOSTINI, P. Exigência nutricional de lisina digestível para galinhas poedeiras no período de 34 a 50 semanas de idade. Revista Brasileira de Zootecnia, v. 36, n. 6, p. 1829-1836, 2007.

SAS - Statistical Analisys System - SAS Institute Inc., SAS/STAT. User's guide. Versão 6.11. 4. ed. v. 2. Cary: SAS Institute Inc., 2000. 842p.

SILVA, D. J.; QUEIROZ, A. C. Análise de Alimentos (métodos químicos e biológicos). 2. ed. Viçosa: Universidade Federal de Viçosa - Imprensa Universitária, 2002. 165p.

UDEH, I. Influence of weight grouping on the short term egg production of two strains of layer type chicken. Animal Research International, v. 4, n. 3, p. 741-744, 2007.

WOLFENSON, D.; FREI, Y. F.; BERMAN, A. Responses of the reproductive vascular system during the egg - formation cycle of unanaesthetised laying hens. Britrish. Poultry Science, v. 23. n. 5, p. 425-431, 1982. 
Autor para correspondência: Paulo Ricardo de Sá da Costa Leite. Instituto Federal Goiano, Campus Ceres, rodovia GO 154, km 03, s/n, zona rural, caixa postal 51, Ceres (GO), CEP 76.300-000. paulo.ricardo@ifgoiano.edu.br 